\title{
Guiding the Guest Experience
}

\author{
Haeeun Helen Chun
}

One of your many jobs as a hospitality manager is to seek ways to improve your guests' experience. You can do this, of course, by making investments to upgrade guest services or provide better products, facilities, and programs, but this is not the only place to invest your money-and it may not even be the best course. As it turns out, guests' perceptions of their experiences can be improved without huge investments. Instead, if you can get your guests to focus on the positive aspects of their experiences, their perceptions of your operation (and their evaluations) will likely improve. The other side of this coin is to avoid calling attention to unpleasant aspects of an experience. In this chapter, I want to discuss ways to encourage your guests to focus on their experience in a positive way (and to minimize attention on unpleasantness). This involves guiding the guest experience.

Guiding the guest experience works like this. Tasting a slice of chocolate cake is pleasurable for most of us, but researchers have found that when people who are eating that slice of cake were also guided to pay attention to their sensations, they felt greater pleasure from the consumption experience compared to people who did not consciously focus on their experience. ${ }^{1}$ You can simulate this experiment informally by comparing the difference between wolfing down a slice of cake (or any food) and slowly savoring it. All of us generally experience frequent and intense positive emotions when we are mindfully attentive to the here and now. ${ }^{2}$ Even in this simple context of having dessert, people can be attuned to the moment-to-moment taste experience, and thereby boost their enjoyment. You can make this happen by helping your guests pay attention to their specific consumption experience and increasing their awareness of the resulting pleasurable sensations. This can increase their enjoyment of the experience.

In this chapter, I outline ways to enhance your guests' perceived experience by increasing their awareness of the positive aspects of their experience, with a particular focus on enhancing guests' awareness of the experiences as they unfold in the moment. Although we focus on real time, I also explain that you can use this concept for both future and past experiences. 


\section{How to Increase Awareness}

We all have had the experience of doing something on "autopilot," when we're not really paying full attention to what we're doing or what's going on around us. In part, we do this in self-defense, to avoid sensory overload. In particular, repetitive actions like eating or commuting often get screened from full awareness. Even enjoyable experiences, like having a piece of cake, can feel dull if we repeat them often. So some of your guests, particularly those for whom a trip or meal out are unusual, will approach your business with excitement and awareness. But many guests, particularly frequent business travelers, are likely to pay little attention to your operation-for them it's just another night in a hotel.

Raising awareness is actually a relatively easy task. It chiefly involves engaging more of your guests' senses and thinking. Helping your guests notice and acknowledge the pleasurable aspects of your hotel can break their habituation and insensibility. Your effort to help your guests become mindful and consciously aware of the pleasures around them can start right at the front desk. Your front-desk associate could point out a facet of your hotel's architectural beauty or even remark to an incoming guest that the weather is beautiful. This type of conversational opening draws your guest into awareness of the moment. The effort by service providers to focus guests' attention becomes more important if you are dealing with extended service encounters such as cruise trips or theme parks, where there is constant opportunity for interaction between consumers and service employees.

The effort to help guests be mindful of the pleasures from their experience can continue as they leave your hotel. One way to do this is to provide cues for awareness. Tour companies, for instance, may hand out photographs or even postcards to tour participants showing activities or locations that they have visited. This way, your guests can relive their travel experience after they return home. Some hotels also hand out a small souvenir to their guests with the same goal in mind.

The cue for mindfulness must be specific. You need to draw your guests' attention to a precise aspect of an experience or of the environment. This is because you want your guests to recognize the value of their stay, and as such, you need to provide cues that move them past a general sense of wellbeing and into a conscious thinking mode. Making guests more mindful of the positives of their stay increases their emotional connection to that source of pleasure, and their general sense of well-being also rises. 


\section{Sources of Pleasure}

As depicted in Figure 8.1, we can identify three general types of pleasure: sensory pleasure, aesthetic pleasure, and achievement pleasure. ${ }^{3}$

Your guests can be attuned to the moment-to-moment pleasurable experience in any or all of these types of pleasure. The sensory pleasures derive from an attractive sight, a lovely sound, a pleasant taste or smell, or a touch or kinesthetic experience. Aesthetic pleasure derives from the senses, of course, but it involves appreciation of the beauty of architecture or nature. The pleasure of achievement can involve actions taken, personal growth, or a renewed sense of self. Already, you can see how hospitality operators may tap into all these types of pleasure and find strategic ways to enhance consumer $\wedge^{\wedge} \mathrm{V}^{*} \mathrm{f}$ pleasure, especially during service encounters. Having people try to notice and acknowledge pleasurable little things that would otherwise go unnoticed (e.g., flowers, sunshine, or music) boosts overall happiness and enjoyment. ${ }^{4}$ As such, enhancing your guests' attention to psychological, physical, or environmental cues will be a key to increasing their enjoyment.

Sensory Pleasure: Pleasure derived from positive physical sensations Examples: Eating a tasty meal, smelling a delightful aroma, or getting a massage at a spa

Aesthetic Pleasure: Pleasure derived from the observation of something that is beautiful, either natural or manmade

Examples: Enjoying a beautiful painting, landscape, or musical piece

Achievement Pleasure: Pleasure derived from attainting something that is desirable or rewarding

Examples: Finishing a good book, winning a competition, eating in a healthier way, or learning about history 


\section{Inkaterra Machu Picchu Pueblo Hotel \\ Jose Loehlin \\ Founder and Chairman \\ Inkaterra}

Inkaterra owns and operates boutique eco hotels in Peru. The first property opened in 1975 to lodge the scientists who came to study the rain forest around Machu Picchu. There are currently hotels in Machu Picchu Pueblo, Cusco (La Casona), and the Amazon jungle (Reserva Amazonica). Soon, Inkaterra Cabo Blanco (where Ernest Hemingway fished) will open the first marine conservation area in Peru. Also, three other projects are in the works, at Cusco City, Urubamba Valley, and Tambopata.

Reviving the spirit of a royal Inca retreat, Inkaterra's boutique Machu Picchu hotel invites visitors to find comfort in its stunning whitewashed cottages nestled into the terraced hills at the foot of Machu Pactiv. Since the early 1970s, Inkaterra has worked as much to study and discover the history and nature of Peru as it has to expose it to the guests of the hotel. Inkaterra is dedicated to supporting ecological research for conservation and renowned for its natural resource management programs.

We pay special attention to entertain guests' various sensory experiences, ranging from placing a hot water bag on the bed for turndown service to serving organic iced tea grown on site at the hotel lobby. Toiletries are also produced in-house using sublime local natural essences and fragrances. Traditional Peruvian cuisine is served at the restaurant situated against a stunning backdrop of the rushing Vilcanota River. Guests can also enjoy peace and tranquility strolling the organic gardens and smelling fresh mint or green tea leaves. The hotel grounds include more than three miles of ecological paths. Inkaterra has also recorded 192 species of birds (18 hummingbird species); 111 species of butterflies, and numerous ferns, orchids, bromeliads, and medicinal plants. It also grows organic vegetables and has an organic tea plantation. Additionally, its orchid garden houses the world's largest collection of orchid species, including new species discovered on the hotel grounds.

Inkaterra has strived to employ the core principles of tourism not just to please guests, but also to provide them with an opportunity for personal learning and growth. To help guests achieve a sense of achievement, Inkaterra offers multiple daily excursions (both on- and offproperty) with trained guides and resident biologists. For example, the complimentary Twilight 
Walk tour is designed to encourage guests to connect with the environment on a spiritual level, by learning about the local culture and participating in rituals of paying respect to Mother Nature. Guests are also invited to Tea Garden tours to experience the traditional teamaking process and learn about its many indigenous plants and animals. Fully guided tours outside the property-hiking up the Machu Picchu citadel and archaeological sites-are also offered. Inkaterra has also actively produced educational materials such as CD recordings of indigenous bird songs and films about local culture, and we support the conservation of native communities and cultural preservation. This highly educational process defines Inkaterra's endeavor to cultivate ecotourism.

\section{Focusing Your Guests on Their Experience}

Let's look at four ways that you can induce your guests to be aware of their experience and to appreciate their stay in your hotel. These methods are to seize the moment (or stress the brevity of pleasures), evoke imagery, turn guests into observers of their own enjoyment, and label experiences using the narrowest possible categories (and have more categories).

Carpe Diem: Stress the "Fleetingness". One of the messages of Stephen Sondheim's musical Into the Woods is summarized in this line: "Opportunity is not a lengthy visitor." To help your guests gain more pleasure from their experiences with your operation, you can stress that the experience won't last long-even if it's a multiple-day cruise. When people become aware of the transient nature of positive experiences, they tend to become more appreciative of the experiences and are motivated to enjoy themselves as much as they can. ${ }^{5}$ We already do this in reaction to life's major transitional experiences, such as marriage or graduation from college. Although such transitions can evoke both pleasure and sadness (bittersweet experiences), people seek the happiness in these situations by proactively extending the moment by participating in numerous related activities-senior week, for example, or bachelor parties. A vacation or a family trip to a theme park is a perfect context where you can accentuate how fleeting the experience truly is. An imminent return from overseas adventure travel is likely to evoke bittersweet feelings-happy to be back home, but sad that it's ending. Thus, the time remaining on the trip feels more precious to your guests, prompting them to engage in more activities (say, taking more photos, setting up farewell dinners). Realizing that their vacation will eventually end, your guests come to appreciate the positive aspects of their vacation and savor their experience more. 
One way you may induce this sense of fleetingness is to frame the remaining time as an evershorter interval. For instance, if your customers are in day five of a six-day trip, you may frame the remaining time as "two days left" rather than "Day 5." This frame makes the remaining time seem more precious. Focused on the transience of their vacation, guests would become more aware of their pleasure and enjoyment. Another implication of bittersweet moments is that the last few days of your guests' vacation are likely to seem even more bittersweet and thus generate stronger emotions than the first few days - since good times are about to end and they have to go back to "reality." To increase opportunities for participation, you could offer such indulgences as fancy meals or room upgrades with a nicer view of the ocean, sign-ups for tours to exotic spots, or chances to purchase pricey souvenirs toward the end of their trip or stay.

Evoke Imagery (for an Uncertain Outcome) in Your Promotion Strategy. Imagery can bring your guests' experience to life, but if you add an element of uncertainty, you can engage their imaginations. Here's how that can work. Imagery creates a web of associations that may help your guests become more mindful of the pleasure brought about by positive experiences. One way you can elicit consumers' imagery is by mixing those images with some component of uncertainty. Consumers who win a lucky draw without being informed of the exact prize may be intrigued by the uncertainty as they imagine and visualize the prize. ${ }^{6}$ This act of imagining favorable prospects helps guests stay happier for a longer duration. As such, being uncertain about some of the details of a positive service experience can capture guests' attention and prolong their enjoyment of the experience (provided that experience is not disappointingly modest compared to their expectations). Here's how one restaurant incorporated this idea into their marketing strategy and implemented a curiosity-inducing promotional strategy. Cafe 50's, a restaurant in Los Angeles, handed their guests a sealed envelope for a New Year's celebration event. To find out the prize they had won, which included a free dessert or cash prize, the guests had to bring back the envelope- unopened-at a future visit. In this way, Cafe 50's encouraged an increase in awareness of this positive state induced by pleasant uncertainty.

Make Guests Observers of Their Own Enjoyment. When your guests can observe others having a good time and enjoying it, they also enjoy the experience as they share the moment. Not all restaurants want the queue to be visible from the dining room, but if your concept permits, you could design your dining area so that waiting guests get views of diners enjoying their experience, as occurs with customers waiting in line for a ride at the theme park. Interestingly, it turns out that allowing people to watch and experience their own responses to experiences also boosts enjoyment. One interesting device that you may adopt along this line is to put up mirrors so that guests can see 
themselves as they enjoy an experience. ${ }^{7}$ Theme parks use this principle by selling photographs of roller coaster riders as they descend the first huge drop. Guests get to observe their own emotional states (usually positive, sometimes anticipating the drop). Likewise, some restaurants take photos of guests enjoying themselves at a birthday party or other celebration, enabling them to observe their responses and remember the experience.

Finer Labeling Makes Your Guests Less Bored Pleasure or enjoyment tends to decline with greater consumption of a particular type of item. Because customers eventually habituate to or satiate from an experience (even the roller coaster), you need to keep it fresh. One way to do this is to increase the variety of choices, so that your guests can find alternatives to their initial choice. You can achieve your goal without necessarily increasing the number of offerings by paying attention to how you label each offering compared to others. ${ }^{8}$ You do this by presenting the offering with a label that fits under specific categories (e.g., finer classification based on flavor, size, texture, color) as opposed to a single general category. Suppose that a confectioner offers two chocolate candies. If the candies are not differentiated, consumers will be satiated (in terms of the tasting experience) with one chocolate, since they seem more or less the same. But when the chocolates are specified under flavor-based categories such as dark chocolate and triple dark chocolate, even though your customers are tasting the exact same set of food items, the finer classification makes them attend to the details that differentiate the items.

The same principle works with wines, for instance. If the choice is merely red or white, your guests will pay less attention (and perhaps buy less) than if you are offering a Pinot Noir, a Cabernet Sauvignon, and a Sangiovese- you draw your guests' attention to differences in the wines. Adding vintages or appellations refines this process even further, and you can increase revenues of your existing products and services without necessarily altering or adding to them-it's all in the categorization. In general, this method is more powerful for novice consumers, but novices and experts both will appreciate your finer labeling as enriching their experience.

\section{Minimize Attention to "Unpleasantries" (Dreads)}

Certain aspects of travel are unavoidably unpleasant, dreary, or merely repetitive. Business travelers may not look forward to staying at your hotel, and even leisure travelers may approach your hotel with an unfavorable mindset if, for instance, they are visiting less-than-favorite relatives or stuck in an unwanted destination. Even small things can become dreads that can take over our cognitive process 
and color what should be an overall pleasant experience and have the opposite effect to the heightened awareness of pleasure. They make the experience seem worse than it would seem to be objectively.

Your strategy here is to find ways to reduce the number or duration of unpleasant or boring experiences. For instance, many companies have set up check-in systems that allow premium customers to circumvent lines at the front desk. Airlines use paperless check-in for this reason-e-mail your boarding pass to your smart phone and you don't even need a printer. Other mobile applications are moving toward a similar goal. For example, especially handy for frequent business travelers, apps such as Tripit reduce unpleasant aspects of travel by consolidating information about flight, hotel, and car rental confirmations in all one place, and by updating information about any changes to departure or arrival times and gates. Hotels that offer their signature cookies at the reception desk are also using this strategy of reducing dreary travel experiences.

You should also strive to offer a certain level of stimulation for those who approach hospitality businesses with an unfavorable or routinized mind-set. ${ }^{9} \mathrm{~A}$ novel or creative presentation of a familiar dish could enhance your guests' awareness of the experience. Even for frequent travelers, adding one or two novel components to an otherwise repetitive experience will likely prevent habituation. For example, you could discreetly place workout clothes in your guests' room to raise awareness of your exercise facilities and encourage the guests to use them-thereby adding variety to their stay. If your guest is a frequent visitor, you might have a record of that person's favorite music and have it playing in the guest rooms upon arrival.

\section{Improving the Experience Before the Guest Arrives}

Let's look at ways that you can set the stage for your guests to think consciously about their future experiences. For many guests, looking forward to their upcoming vacation trips or fancy dinners is part of the pleasure of the trip. Thus, you want to make sure your customers take full pleasure in their anticipation. People who anticipate their future experience and are attentive to their current emotional state not only derive pleasure from anticipation, but they are likely to end up enjoying the event more. Thus, if you find ways to better manage your consumers' pre-event experience, you will probably boost their satisfaction with the service. This can happen when restaurants send out invitations for Valentine's Day or Christmas dinner with a special menu, or when hotels promote special vacation packages with photos of the destination. These two tactics try to tap into consumers' anticipation before the experience occurs. 
Manage the Physical Wait to Increase Anticipation

Perhaps the most critical time to influence guests' anticipation of the pleasure of a service is when they are waiting in a queue. No one likes to wait, so hospitality operators have devised many approaches to make waiting more palatable. Disguising the length or configuration of the queue (e.g., a snake line) or giving guests something to distract or divert them while waiting (e.g., music, a television screen, or waiting room magazines) may draw their attention so that they perceive the wait time to be shorter than it actually is. Busch Gardens theme park in Tampa takes this principle one step further by allowing guests waiting for the Congo River Rapids water ride to participate while they wait by aiming water jets at those already on the ride, thereby soaking the riders (who will get wet anyway) and increasing the fun for all. This wait is also a chance for you to invite your guests to consciously think about the upcoming experience and enjoy the good feelings in advance, rather than simply diverting them to reduce their frustration. Such anticipation should highlight the enjoyment of the actual experience and thus make it more memorable.

Here's how you can utilize relatively brief waiting times (such as in a restaurant or at the theme park). As a restaurant manager, you could display dessert samples in an attractive display that will both heighten anticipation and somewhat decrease the boredom of waiting. The Stock-Yard Restaurant in Nashville, for instance, is one of many steakhouses that display the actual cuts of meat in a refrigerator case, and many seafood restaurants have a tank with the lobsters right out front. Both are meant to engage the guests in the upcoming pleasure of their meal, even as they wait for a table. You could also design the waiting area with a view of the kitchen so that they can observe the cooking and experience the aroma of the food in advance. Some restaurants even provide sample bites or wine tastes while the guests are waiting in line.

\section{Addressing Restaurant Wait Times \\ Mark Censoprano \\ Chief Marketing Officer \\ Sbarro, Inc.}

In table-service restaurants, one contributing factor to the guest experience is the wait. The wait is one of the first impressions that a guest has of a restaurant, and so it is an important part of their overall dining experience. Initiatives that help reduce the wait or make 
the wait more enjoyable can help make the difference between excellence and mediocrity. Both approaches address the principle of respecting the guest's time.

The following are initiatives that are designed to reduce the wait, or specifically to reduce idle time in a lobby:

- Call-ahead seating, which gives the guest a target time for arrival and allows guests to determine where they wait

- Online reservations and monitoring of table availability, which can be linked directly to a restaurant's table management system

- Paging systems that ring a guest's cell phone so they can leave the premises to make better use of their time

Beyond tightening the wait time, many restaurants take advantage of this opportunity by meeting the immediate needs of the guest and also implementing initiatives that support their brand positioning. Here are examples of programs that can address the wait wisely and build a brand at the same time:

- Inviting, engaging, sensory pleasing bar areas that serve food or beverage items

- Lobby music specifically designed to improve the productivity and morale of linelevel employees and the attitudes and spending behaviors of dining patrons (Muzak is the longest-running such service, and a more recent purveyor is Ambiance Radio ${ }^{\mathrm{TM}}$, founded by a graduate of the Cornell Hotel School.)

- "Feature of the Day" menu boards to educate guests and accelerate the ordering process

- Serving samples of a restaurant's most popular food or beverage items, or showcasing new items on the menu

- Wine sampling, which can make wine less intimidating and introduce guests to new varieties or producers

Improving the guest experience through enhancing the wait is predicated on a restaurant's ability to flawlessly execute its initiatives. Hot food samples should be hot; cold beverages samples, cold. Music loud enough to enjoy, but not too loud to distract. Quotes for wait times that aren't too unrealistically short, but not so long that guests leave. Running a restaurant is certainly a complex undertaking, and the more a restaurant company can design their systems and processes to support excellent execution, the better. Managing the dreaded "wait" is no exception. 
An example of a practice that cleverly transformed the normally boring physical wait into an enjoyment-boosting device is the Universal Studio's Simpsons Ride, a simulator ride based on the television show. The wait line for this popular ride is designed for guests to watch the preshow clips featuring the Simpsons in multiple steps of waiting rooms, each with a theme designed to introduce guests to the storyline of the ride. The guests are already part of the characters in the storyline even before getting on the actual ride, and the wait line becomes part of the attraction. Once again, the guests get to think about the upcoming ride with excitement during their wait. This strategy goes beyond often-discussed strategies of simply diverting guests' attention away from unpleasant matters to other pleasant environmental cues or soothing their emotions with fun music. In sum, the way to think about this is to design the wait period to be productive and enjoyable with anticipation, in such a way that it supports the enjoyment of the main experience. In many cases, a sense of festivity of an enjoyable service experience can begin in the waiting line if that wait period is incorporated into the entire service experience. These principles also apply if your service involves an experience that may generate anxiety or fear (like waiting in the hospital). You still need to design a waiting area that can reduce stress and that is comfortable and soothing. In this situation, the waiting time can give people an opportunity to cope with the stress and the impending event. ${ }^{10}$

\section{Maximizing Anticipation after Guest Reservations}

Let's take a look at how to make use of the longer wait period that occurs after your guests have reserved a trip or a future dining experience. As a hospitality operator, you have the opportunity to make contact with your customers well before consumption occurs, something that other businesses would greatly desire. Once you have the reservation, you know your guests' names and contact information in advance. As with the shorter queue-based wait, you can use that waiting period to improve guests' experience by strategically shaping this wait period to enhance the service experience.

One way to manage your guests' waiting period is to send informative brochures featuring your on-site facilities and nearby attractions. Make sure your Web site is well designed and useful, so that it provides menu descriptions and reviews, if appropriate, or offers a slideshow (or video) of your facility. Beyond that, you can use more sophisticated means to further engage the guests during the wait period. For example, if leisure travelers book a hotel room or a cruise trip weeks ahead of their trip, you can segment the waiting time into a time period when you send your guests relatively general information (usually the earlier period) and then have a time period closer to the arrival date when you send more concrete and specific information, with vivid visual aids. 
This approach fits the psychological principle of construal level theory. This theory notes that people tend to think globally and abstractly regarding activities or events that are in the relatively distant future. At this time, they think about such matters as the "why" aspect of actions and the overall desirability of events. By contrast, for the near future situations, your guests tend to think more concretely a level of how, when, and where they'll perform the activity. So, in the context of planning for a vacation, when that vacation is still far away consumers tend to picture it broadly in the context of a bigger goal like having fun, having a quality family time, or engaging in a challenging adventure. However, as the vacation time approaches, the details of the vacation, the context in which the events occur, and possible alternative episodes that might occur during the vacation may become more salient. So it makes sense for you to match the sequence of information you send out with consumers' general tendency to construe situations according to the event's proximity. Also, by sending the information at different points of time, you can engage guests to look forward to the upcoming event throughout the entire waiting period.

Social media and mobile apps are also potentially useful tools to manage consumers' preconsumption experience. One logical thing to do is to tweet guests who have booked their hotel rooms and update them with relevant information over time. This has the effect of inducing excitement and anticipation - as well as providing needed knowledge. Early on, you can send information or simply offer entertaining material (like photos). What matters most is to remind guests of the upcoming event and provide them with the frequent moments of anticipation. Mobile apps can also be designed with the same goal in mind. Again, the festivities should begin the moment you have your guests' booking information.

Before I close, it's important to mention what should be a self-evident caveat to the idea of turning your guests' waiting experience into a time of happy anticipation. Your operation must be able to deliver on the expectations that you have created. Thus, the consumer's actual experience must not be drastically different from what is expected. Your effort to keep your promises should be part and parcel with your effort to keep them informed and entertained during the wait.

The ideas presented here (summarized in Figure 8.2.) will help you to constantly improve your guests' experience by heightening their awareness of the pleasurable experiences they will have, are having, and did have in connection with your operation - that is, before, during, and after their visit. 
Figure 8.2

How to Guide the Guest Experience Before, During, and After the Visit

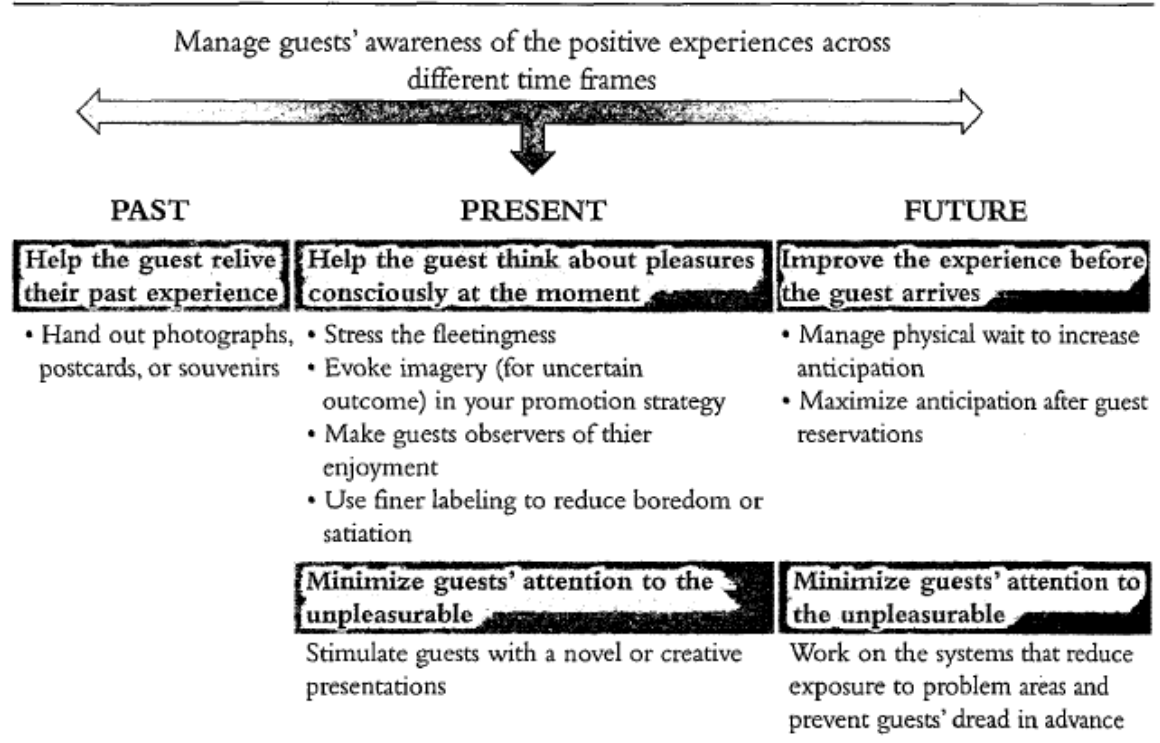

\footnotetext{
${ }^{1}$ J. L. Le Bel and L. Dube, "The Impact of Sensory Knowledge and Attentional Focus on Pleasure and on Behavioral Responses to Hedonic Stimuli," Paper presented at the 13th annual American Psychological Society convention, Toronto, Ontario, Canada, 2001.

${ }^{2}$ S. Lyubomirsky, The How of Happiness: A Scientific Approach to Getting the Life You Want (New York: Penguin Press, 2008).

${ }^{3}$ F. B. Bryant, and J. Veroff, Savoring: A New Model of Positive Experience (Mahwah, NJ: Erlbaum, 2007); K. Duncker, "On Pleasure, Emotion, and Striving," Philosophy and Phenomenological Research 1 (1941): $391-430$.

${ }^{4}$ M. E. P. Seligman, T. Rashhid, and A. C, Parks, "Positive Psychotherapy," American Psychologist 61(8) (2006): 774788.

5 J. L. Kurt, "Looking to the Future to Appreciate the Present: The Benefits of Perceived Temporal Scarcity," Psychological Science 19(12) (2008): 1238-1241; and Bryant and Veroff, 2007.

${ }^{6}$ Y. H. Lee, and C. Qiu, "When Uncertainty Brings Pleasure: The Role of Prospect Imagineability and Mental Imagery," Journal of Consumer Research 36 December 2009): 624-633.

${ }^{7}$ J. W. Schooler, D. Ariely, and G. Loewenstein, "The Pursuit and Assessment of Happiness May Be Self-Defeating." In I. Brocas and J. D. Carrilo, eds. Psychology and Economics, Volume i: Rationality and Well-Being (New York: Oxford University Press, 2003), 41-70.

8 J. P. Redden, "Reducing Satiation: The Role of Categorization Level," Journal of Consumer Research 34 (February 2008): 624-634.

${ }^{9}$ 9. Bryant and Veroff, 2007.

${ }^{10}$ See E. G. Miller, B. E. Kahn, and M. F. Luce, "Consumer Wait Management Strategies for Negative Service Events: A Coping Approach," Journal of Consumer Research 34 (February 2008): 635-648.
} 